\title{
4-H teens learn to lead science program for kids
}

\author{
Martin H. Smith \\ Richard P. Enfield \\ Cheryl L. Meehan \\ Donald J. Klingborg \\ $\nabla$
}

To improve science literacy among school-age children in the United States, educators must receive effective training and support, and children must be engaged in science at a young age. Animal Ambassadors is a science-education outreach program of the UC School of Veterinary Medicine, Veterinary Medicine Extension, which focuses on the awareness and understanding of animal-related concepts and emphasizes important critical thinking and life skills. Through a collaboration with UC Cooperative Extension's San Luis Obispo County Youth Development Program, an Animal Ambassadors research project showed positive outcomes relative to interrelated goals involving teen training and youth science literacy.

$S_{d}^{c}$ cience literacy among school-age children is a state and national concern. Results from the Third International Math and Science Study (TIMSS) showed that science literacy among U.S. high school seniors is among the worst in the developed world (Hiraoka 1998). The 1999 TIMSS-Repeat, a follow-up test designed to monitor trends, indicated that performance in science by younger children in the United States was declining (TIMMS 1999; NCES 2000). Furthermore, in 2000, 4thand 8th-grade students in California scored last on a nationwide science test (O'Sullivan et al. 2002).

In order to develop a scientifically literate population, it is crucial to engage children in science activities at an early age (Rubin 2002). Most educators who work with young children do not feel qualified to teach science (Fulp 2002), and

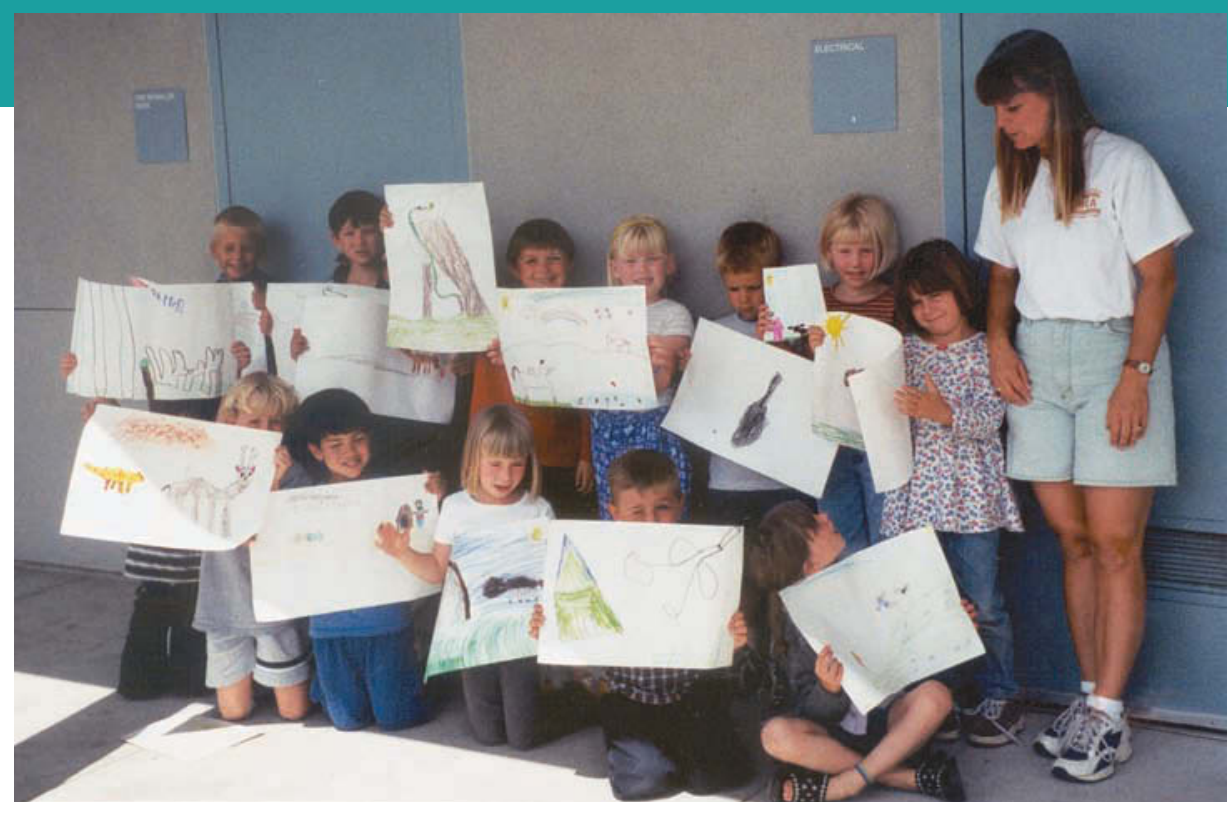

A program of the UC Davis Veterinary Medicine Extension, Animal Ambassadors seeks to stimulate interest in science through hands-on activities. Children from the San Luis Obispo County YMCA display their artwork from an Animal Ambassadors curriculum activity. science teaching at the elementary-school level is regarded as the weak link in science education (Dana et al. 1997). In order to improve their teaching skills, teachers who work with this age group must receive effective training and support.

\section{Animal Ambassadors}

Animal Ambassadors is a youth science-education outreach program of the UC School of Veterinary Medicine, Veterinary Medicine Extension, at UC Davis. Initiated in 1999, the program aligns with California science-content standards and is designed to stimulate an interest in science through the use of a hands-on curriculum that emphasizes the Scientific Thinking Processes (observing, communicating, comparing, organizing, relating, inferring and applying)(Lowery 1992) and life skills (such as communication, teamwork, problem-solving and recordkeeping)(Hendricks 1998). The curriculum activities use inquiry methods that emphasize having children discover knowledge through their own exploration. Furthermore, the Animal Ambassadors curriculum is made interactive through the use of hands-on alternatives to live animals (such as rubber foot molds, plaster tooth casts and imitation animal coats) that are organized into learning kits. The activities are developmentally appropriate and organized around five major concepts: animal habitats and geography, structure and function, dietary needs and habits, animal communication, and human-animal interactions (Smith and students 2002).

In 1999 and 2000, the 4-H Youth Development Program in San Luis Obispo County received funding for a collaborative research project involving the Animal Ambassadors program, entitled "Animal Ambassadors - A Science Education Outreach Model." The project was structured around two interrelated goals: to develop a state and national training model for implementation and
It is crucial to engage children in science activities at an early age; but most educators who work with young children do not feel qualified to teach science. 


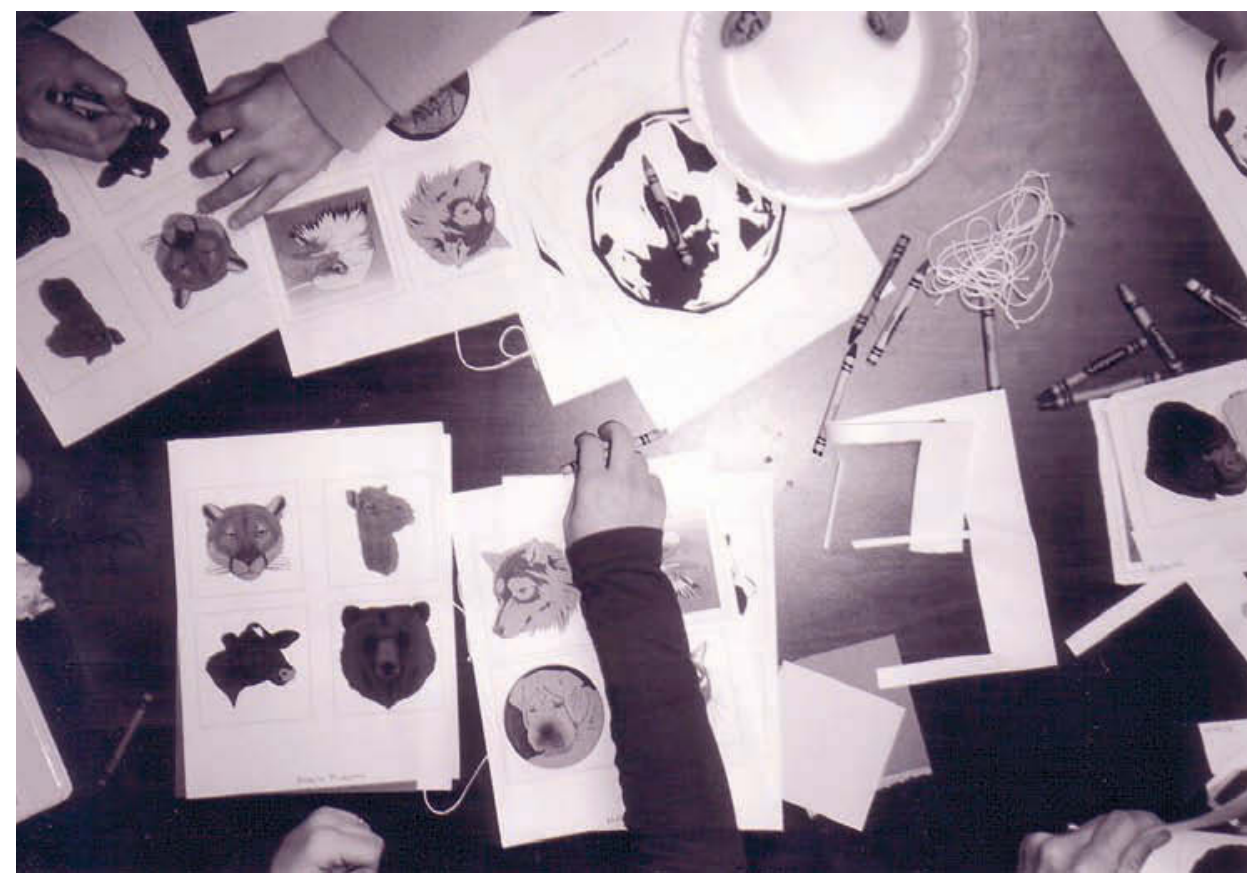

4-H teen teachers from San Luis Obispo County prepare to practice the "World of Art" activity during an Animal Ambassadors curriculum-training workshop.

dissemination of the Animal Ambassadors science-education program, and to increase the science literacy of youth ages 5 to 8 .

As the key component to state and national dissemination and implementation, project leaders designed and tested a "Step-Up" Incremental Training Model. A series of three workshops alternated with curriculum implementations that emphasized progressive skills development, such as understanding and using inquiry, effective questioning strategies, age-appropriate language and small-group instruction (Smith and Enfield 2002). Through increased skills, practice and instruction, the sequenced trainings are designed to progressively increase the competencies of the program's teachers over an extended period of time. This model was designed using 4-H teens, but has also been tested and shown effective with adult volunteer leaders (Smith et al. in press).

\section{Implementation by 4-H volunteers}

In the Animal Ambassadors model project, teens were used as cross-age teachers of younger youth, a common practice in 4-H youth development programs (Lee and Murdock 2001). In San Luis Obispo County, a call for volunteers went out to 4 - $\mathrm{H}$ teen members via the 4-H monthly newsletter and direct recruitment letters, and indirectly through letters to 4-H community club leaders asking for their assistance in identifying teens interested in participating in this project. Twenty-four teens from three clubs (Cerro Alto, Shandon and Parkfield) in different geographic locations were recruited; 15 teens completed the project. Attrition was due principally to transportation issues; some teens had to travel more than 90 minutes each way to participate in the curriculum trainings. The 15 teens that completed the project attended all trainings and curriculum implementations, and all data used in the analyses is from this cohort.

The San Luis Obispo County 4-H teens attended three curriculumtraining workshops at the UC Cooperative Extension San Luis Obispo County office over a 3-month period beginning in early February and ending in late April 2000. Training workshops focused on introducing teens to the fundamentals of inquiry-based learning, and workshop facilitators modeled activities to reinforce effective methodology. Teens practiced the Animal Ambassadors curriculum in front of their peers in advance of implementation with young children, and significant time was allotted during trainings for reflection and review.

Working in teams, the teen teachers implemented the Animal Ambassadors curriculum activities during 14 sessions with primary 4-H members and young children of similar ages at two YMCA programs (Los Ranchos and Pacheco Day Camp). Implementation spanned either 7 or 14 weeks, depending on

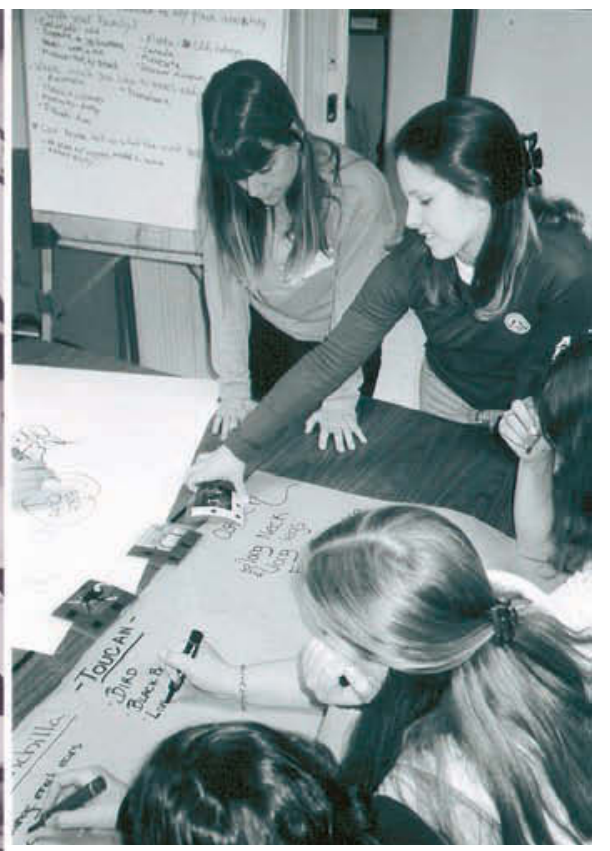

Andrea Laubscher, a 4-H program representative from San Luis Obispo County 4-H, works with 4-H teen teachers.

whether the curriculum activities were scheduled on a weekly or biweekly basis.

\section{Evaluating outcomes}

During teen curriculum-training workshops, an emphasis was placed on effective questioning strategies. Understanding the difference between closed and open-ended questions, and applying this knowledge during instruction, is important to the successful implementation of inquiry-based activities. Closed questions typically have only one correct answer (such as, What type of teeth do animals use to grind food?) — the recitation of a fact - and are poor indicators of a student's true understanding of a concept (Latham 1997). Conversely, openended questions do not necessarily have right or wrong answers (such as, What do you know or wonder about different types of animal teeth?); rather, they encourage students to explore possible answers or solutions to problems or situations through group interactions and independent thought (Ciardiello 1998). Learning environments where educators practice the use of open-ended questioning promote the value of multiple ideas and perspectives and find students becoming more responsible for their own learning by generating their own questions (Martens 1999).

Multiple assessment measures were used to determine change in the teens' understanding and use of question- 

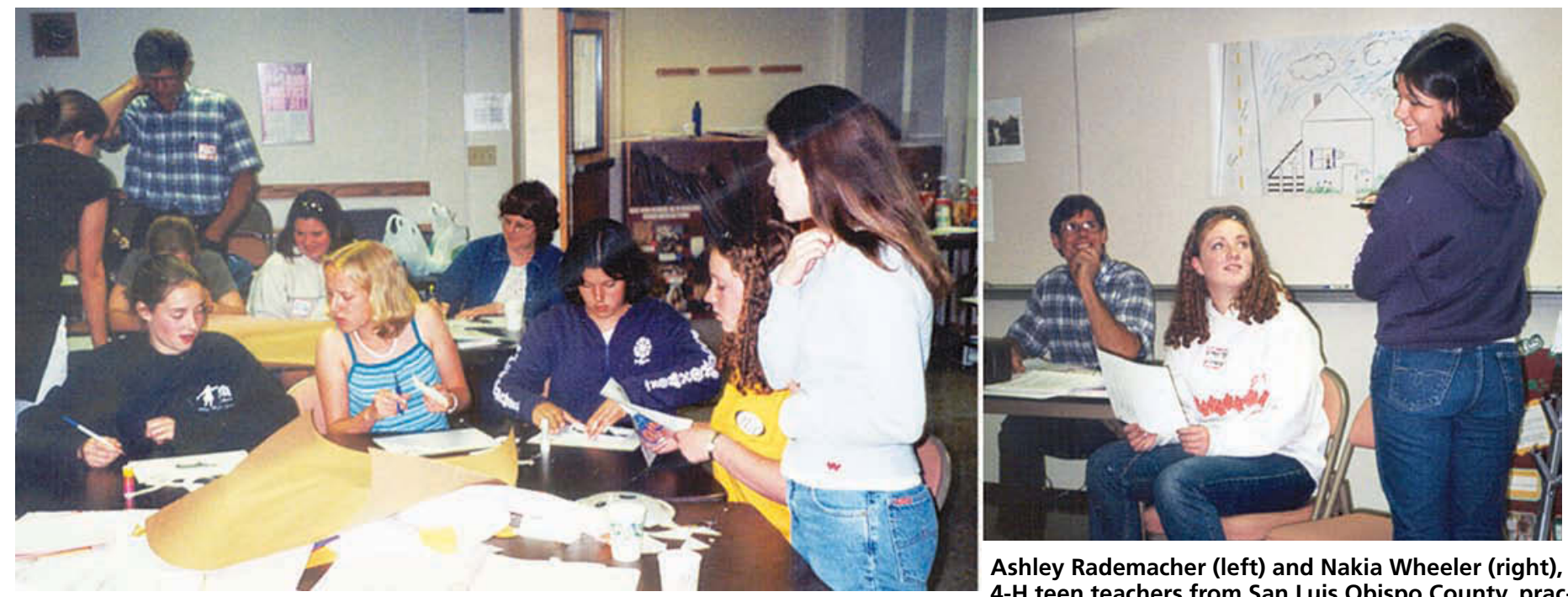

4-H teen teachers, adult volunteer leaders and 4-H county staff work in teams during an Animal Ambassadors curriculum-training workshop.

Ashley Rademacher (left) and Nakia Wheeler (right), 4-H teen teachers from San Luis Obispo County, practice effective questioning strategies under the helpful eye of Jim Dewing, a 4-H adult volunteer leader.

ing strategies. Direct observations of curriculum implementations allowed researchers to compare the numbers of open and closed questions. A chi-square analysis of the data over the course of the three trainings revealed that the amount of training teens received did have a significant relationship with the types of questions they used during curriculum implementations (chi-square $=$ 23.5, $P=0.001$, $\mathrm{df}=2$; fig. 1). Furthermore, when asked during the focusgroup interview how their participation in this project affected their approach to asking questions, the teens reported using more open-ended questions in numerous everyday situations.

\section{Science skills in children}

Program evaluators were looking for changes in the type and quality of the children's descriptions using the Scientific Thinking Processes. Changes were

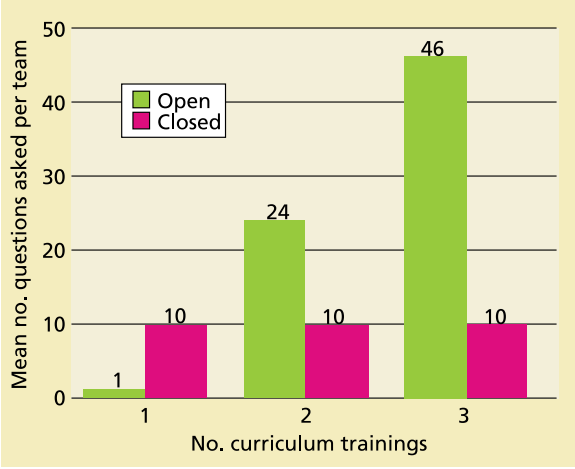

Fig. 1. Change in the types of questions asked by teen teaching teams (four teams at each time point) during the curriculum implementations following the three trainings. measured using a performance-based "object description" assessment tool designed for this study. Children were given and asked to verbally describe two different objects (pre- and posttest) that were independent of the curriculum content. An audiotape of each description was made, and data were scored using written transcriptions of the audiotapes.

A total of 61 children participated in the Animal Ambassadors curriculum implementation over the course of the project. Because participation was voluntary and not every child was present when the pre- and post-intervention data was collected, data from 19 pre-/ post- matched sets (eight boys; 11 girls) of children was analyzed. Data was quantified using a scoring rubric that measured the types of Scientific Thinking Processes and the manner in which they were used. The scoring rubric was: no observations or inferences made when describing the object, score $=0$; observations made but no inferences, score $=1$; observations and inferences made but inferences not based on observations, score $=2$; and observations and inferences made and inferences based on observations, score $=3$. A repeatedmeasures ANOVA was used to assess change in scores from pre- and post-test administrations of the object description tool. Results showed a significant improvement in Scientific Thinking Process score from pre-test (mean score $=$ 1.55 , standard deviation $[\mathrm{SD}]=0.74)$ to post-test (mean score $=2.03, \mathrm{SD}=1.05)$ administrations $\left(F_{(1,35)}=6.07, P=0.025\right)$.

\section{Implications and recommendations}

Effective training. The goals of the Animal Ambassadors - A Science Education Outreach Model project were interrelated. In order to have an impact on the target audience, it was essential that the training program for teen teachers be grounded in curriculum content and inquiry methodology. To accomplish this effectively, the curriculum trainings were planned in increments and delivered over an extended period of time. Loucks-Horsley et al. (1998) support this approach, stating that in-service training "confined to short, discrete events is a wasted effort." Additionally, Loucks-Horsley et al. maintain that effective in-service trainings require the participants to have direct experience in the learning they want their audience to encounter, and that this requires time, reflection and open communication with colleagues. The "Step-Up" Incremental Training Model meets these requirements. Over the course of the three-training sequence, $4-\mathrm{H}$ teen leaders gained the competence and confidence necessary to become effective facilitators of the Animal Ambassadors curriculum.

4-H leaders as cross-age teachers. Consistent with other studies involving 4-H teens as cross-age teachers of younger children (Ponzio et al. 2000), the teen leaders were effective in reaching their target audience and derived positive benefits themselves through their participation. To help facilitate the teens' success in their roles as cross-age 


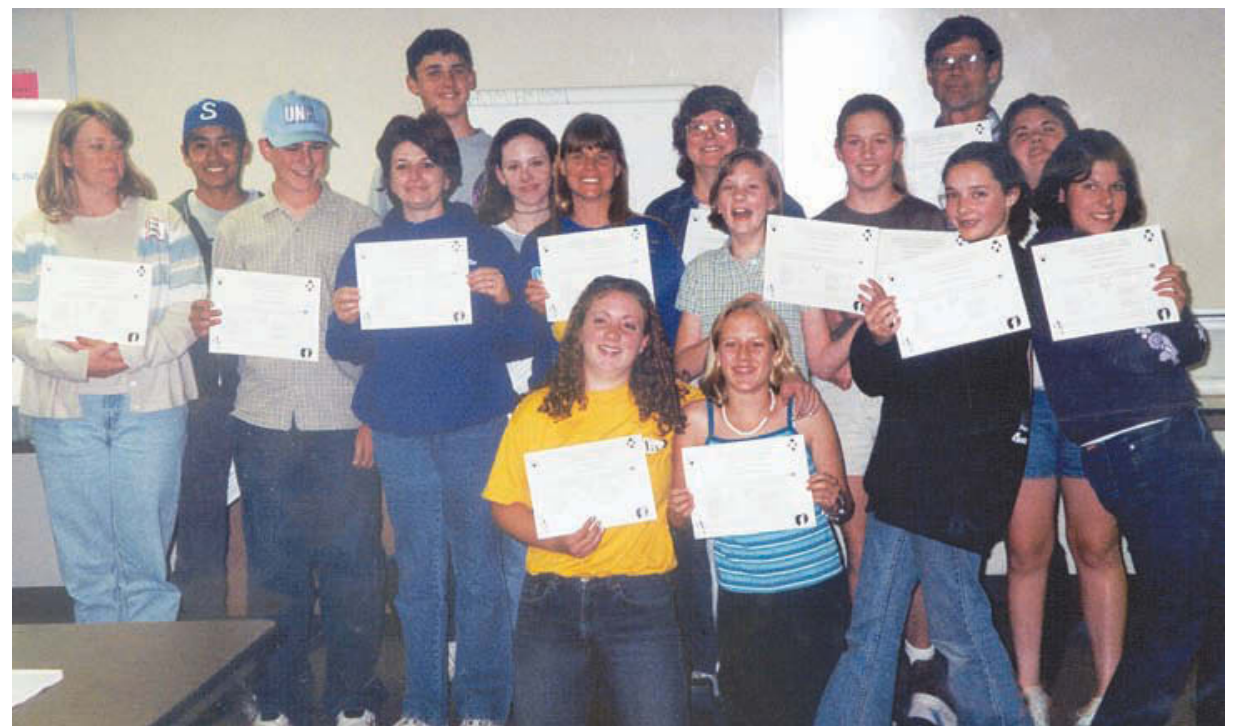

4-H teen teachers and adult volunteer leaders who completed the Animal Ambassadors training and implementation project in San Luis Obispo County display their diplomas.

science teachers, as well as their learning and growth over the course of the project, they received full and continued support. County and campus-based academic personnel and 4-H adult volunteer leaders were responsible for overall project organization and logistics, which allowed the teens to concentrate on their role of implementing the curriculum with young children. Ponzio et al. (2000) note that this helps make teens more effective as cross-age teachers by allowing them to concentrate and focus on their instruction.

\section{Encouraging inquiry}

Most science taught in the United States is done using didactic methods lectures and presentations - that do not promote exploration or independent thought (Jorgenson and Vanosdall 2002). However, according to Marlene Thier (Teacher Education Coordinator, Science Education for Public Understanding Program, Lawrence Hall of Science, Berkeley, personal communication, Nov. 21, 2002), the goal of science literacy is to "have students become independent learners." The hands-on, inquiry-based approach to science education arouses children's curiosity and holds their interest (Hinman 1999). It allows children the opportunity to construct knowledge through their own exploration and helps them to seek new information and understanding by becoming independent learners and thinkers (Richetti and Sheerin 1999).

UC has been called upon to help develop a scientifically literate population that can be successful in the modern world (Price and Cardullo 2000). If the goal of science literacy - developing independent learners - is to be achieved, inquiry-based instruction and programs such as Animal Ambassadors will need to become more prevalent. Furthermore, in order to prepare those who teach science to use inquiry and use it effectively, it is important that they receive training and support that occurs over an extended period of time and in a manner that builds capacity through improved competence and confidence.

M.H. Smith is Assistant Cooperative Extension Specialist, Veterinary Medicine Extension, School of Veterinary Medicine, UC Davis; R.P. Enfield is 4-H Youth Development Advisor, UC Cooperative Extension, San Luis Obispo County; and C.L. Meehan is Post-Graduate Researcher, and D.J. Klingborg is Doctor of Veterinary Medicine and Associate Dean of Extension and Public Programs, School of Veterinary Medicine, UC Davis. The American Honda Foundation provided funding for this research.

\section{References}

Ciardiello AV. 1998. Did you ask a good question today? Alternative, cognitive, and metacognitive strategies. J Adolescent Adult Literacy 42(3):210-9.

Dana T, Campbell LM, Lunetta VN. 1997. Theoretical based science teacher education. Elementary School J 97(4):419-33.

Fulp SL. 2002. Status of Elementary School Science Teaching. 2000 National Survey of Science and Mathematics Education.
www.Horizon-research.com

Hendricks PA. 1998. Developing Youth Curriculum Using the Targeting Life Skills Model: Incorporating Developmentally Appropriate Learning Opportunities to Assess Impact of Life Skill Development. Ames, IA: lowa State Univ Extension.

Hinman RL. 1999. Scientific literacy revisited. Phi Delta Kappan 81(3):239.

Hiraoka L. 1998. The international test scores are in. (U.S. students do not do well.) NEA Today 16(9):19.

Jorgenson O, Vanosdall R. 2002. The death of science? What we risk in our rush toward standardized testing and the three R's. Phi Delta Kappan 83(8):601-5.

Latham A. 1997. Asking students the right questions. Ed Leadership 54(6):84.

Lee FC, Murdock S. 2001. Teenagers as teachers programs: Ten essential elements. J Extension 39(1). www.joe.org

Loucks-Horsley S, Hewson P, Love N, Stiles K. 1998. Designing Professional Development for Teachers of Science and Mathematics. Thousand Oaks, CA: Corwin Pr. 325 p.

Lowery LF. 1992. The Scientific Thinking Processes. Full Option Science System (FOSS). Lawrence Hall of Science, Berkeley, CA.

Martens ML. 1999. Productive questions: Tools for supporting constructivist learning. Sci Children 53:24-7.

[NCES] National Center for Education Statistics. 2000. Highlights from the Third International Mathematics and Science Study-Repeat (TIMSS-R). http://nces.ed.gov/ timss/timss-r/highlights.asp

O'Sullivan CY, Lauko MA, Grigg WS, et al. 2002. The Nation's Report Card: Science 2000. http://nces.ed.gov/nationsreportcard/pubs/ main2000/2003453.asp

Ponzio RC, Jung SK, Smith MH, et al. 2000. 4-H teens as science teachers of children. Braverman MT, Carlos RM, Stanley SM (eds.). Advances in Youth Development Programming. DANR Pub 3401. Oakland, CA. p 75-91.

Price MV, Cardullo RA. 2000. UC must take the lead on curriculum reform, teacher training. Cal Ag 54(1):56-62.

Richetti C, Sheerin J. 1999. Helping students ask the right questions. Education Leadership 57(3):58-62.

Rubin P. 2002. Start young! Sci Children 40(2):25-7.

Smith $\mathrm{MH}$, and students. 2002. Animal Ambassadors - A Bridge to the World of Science. Lower Elementary Curriculum. Veterinary Medicine Extension, School of Veterinary Medicine, UC Davis.

Smith MH, Enfield RP. 2002. Training 4-H teen facilitators in inquiry-based science methods: The evaluation of a "step-up" incremental training model. J Extension 40(6). http://www.joe.org

Smith MH, Meehan CL, Enfield RP, et al. In press. Improving county-based science programs: Bringing out the science teacher in your volunteer leaders. J Extension.

[TIMSS] Third International Math and Science Study. 1999. International Science Report. Findings from IEA's Repeat of TIMSS at the Eighth Grade. http://isc.bc.edu/timss1999i/ science_achievement_report.html 